\title{
Psychosocial management of diabetes: Applicability of national guidelines to Mewat, an underserved region of Haryana
}

\author{
Arun Kumar, Pawan K. Goel, Brij M. Vashisht, Kundan Mittal ${ }^{1}$ \\ Departments of Community Medicine, 'Paediatrics, Shaheed Hasan Khan Mewati Government Medical College, Nalhar, Mewat, Haryana, India
}

\section{A B S T R A C T}

Mewat, a district of Haryana state in India, has unique and different socio cultural milieu which can limit the effective implementation of national guidelines on psychosocial management of diabetes. We reviewed and discussed the underlying socio-cultural and demographic characteristics of Mewat district in order to tailor these national guidelines according to the applicability to improve implementation. We also proposed possible multifaceted interventions/solutions to overcome the potential hurdles for successful implementation of the guidelines in the district.

Key words: Diabetes, guidelines, India, management, Mewat, psychosocial, recommendations

\section{INTRODUCTION}

We were pleased to read the national guidelines for psychosocial management of diabetes in India. ${ }^{[1]}$ Indian populations have varied socio-cultural and demographic characteristics. ${ }^{[2-5]}$ Unique and differential socio cultural milieu of Mewat can limit the implementation and translation of these national guidelines into improved population outcomes. We reviewed and correlated the underlying socio-cultural and demographic characteristics of Mewat district of Haryana state in order to tailor the national guidelines for psychosocial management of diabetes according to applicability to improve implementation.

This narrative review of literature about socio-cultural and demographic characteristics prevalent in Mewat district was conducted on PubMed, Medline, EMBASE, Google

\begin{tabular}{|c|l|}
\hline \multicolumn{2}{|c|}{ Access this article online } \\
\hline Quick Response Code: & Website: \\
\hline & www.joshd.net \\
\hline & \\
\hline
\end{tabular}

Scholar, and other databases, to access relevant and the latest information. The websites of the Government (Govt.) of India and subservient offices/ministries, Govt. of Haryana, Mewat Development Agency, Mewat Development Society, World Health Organization, and news agencies were also searched. The information so collected was collated, summarized, and analyzed to know how the national guidelines of psychosocial management of diabetes be tailored according to the applicability to improve implementation.

The three domains of classification of the national guidelines were: General, psychological, and social. ${ }^{[1]}$

\section{GENERAL ISSUES}

Availability of health workforce, especially doctors, in Govt. and private sectors is itself a challenge in Mewat. The doctors whoever were available had extra workload, and thus had less available time to spend on psychological counseling of diabetics [Tables 1 and 2]. Therefore, motivation and targeted improvement of skills of existing health care professionals in such region is particularly important. Govt. of Haryana, to some extent, has attempted to fulfill this gap by providing extra incentives to Govt. doctors serving in Mewat.

Corresponding Author: Dr. Arun Kumar, Department of Community Medicine, Shaheed Hasan Khan Mewati Government Medical College, Nalhar, Mewat, Haryana, India. E-mail: arun.pgims@gmail.com 


\begin{tabular}{|c|c|c|c|}
\hline Characteristics & India & Haryana & Mewat \\
\hline Population (Mn) & $\sim 1210$ & $\sim 25.4$ & $\sim 1$ \\
\hline Population density (per sq km) & 382 & 573 & 723 \\
\hline Decadal growth (\%) & 17.7 & 19.90 & 37.93 \\
\hline $\begin{array}{l}\text { Percentage of population living in rural/ } \\
\text { urban area (\%) }\end{array}$ & rural $=68.84 ;$ urban $=31.16$ & Rural $=65.12 ;$ urban $=34.88$ & rural $=88.61 ;$ urban $=11.39 \%$ \\
\hline Literacy rate $(\%)$ & $73.0($ males $=80.9 ;$ females $=64.6)$ & $\begin{array}{l}75.65(\text { males }=84.1 \\
\text { females }=56.9)\end{array}$ & $54.1($ Males $=69.9 ;$ females $=36.6)$ \\
\hline Gender ratio (females per 1000 males) & 943 & 879 & 907 \\
\hline $\begin{array}{l}0-6 \text { years child gender ratio (females per } \\
1000 \text { males) }\end{array}$ & 919 & 834 & 906 \\
\hline
\end{tabular}

${ }^{*} \mathrm{Mn}$ : Million

\begin{tabular}{|c|c|c|c|}
\hline Health facility & $\begin{array}{l}\text { Recommended (in view of Indian } \\
\text { Public Health Standards) }\end{array}$ & Mewat scenario[6] & $\begin{array}{l}\text { Gap required to be filled as per Indian } \\
\text { Public Health Standards/Remarks }\end{array}$ \\
\hline General hospital & 300 beds $^{[7,8]}$ & One 50 bedded hospital[9] & $\begin{array}{l}250 \text { beds (Currently } 400 \text { bedded Govt. Medical } \\
\text { College has been set up in the region and is } \\
\text { sharing the load to fill the gap) } \text { ) }^{[10]}\end{array}$ \\
\hline Community health centers & $10^{[11]}$ & $3^{*}$ & 7 \\
\hline Primary health centers & $33^{[12]}$ & $13^{*}$ & 20 \\
\hline Sub-centers & $200^{[13]}$ & $71^{*}$ & 116 \\
\hline
\end{tabular}

*More health facilities are in the process of being set up in the district. ${ }^{[6]}$

Though formal or informal training of the available health care professionals in the form of sensitization to the psychological needs of patients with diabetes in Mewat is likely to help, introduction of trained counselors seem to be an additional feasible intervention required to fill this gap.

In the light of poor literacy rate i.e., $54.1 \%$ (Males $=69.9 \%$; Females $=36.6 \%$ ), improving awareness among patients, and among general population, is another challenge that could be overcome by using country specific modules as described in the guidelines [Table 1]. ${ }^{[1]}$

With low literacy rate and curses like-ignorance and blind beliefs or myths, living in closed shells, simply cut-off from the developmental work, so much so that the diabetics and the general population will not be even aware of the ill health, facilities, and schemes operating around them. For generating awareness among the masses in the district, Radio Mewat could serve as a potential tool by disseminating key messages tailored in Mewati dialect. ${ }^{[14]}$

Adopting a holistic approach for communicating with a patient in Mewat expectedly requires plenty of time, which would really be a challenge for a physician alone because he would be already loaded with the responsibilities of treatment of patients as mentioned earlier. However, few days in a week could be fixed to follow-up such patients and discuss the issues such as outcomes, etc.
Ramadan is a special month of the year for Muslims, Meos in Mewat. During the daylight hours, they totally abstain from food, drink, smoking, and marital sex. ${ }^{[15]}$ In a clinic-based multinational study conducted in Muslim patients in 13 countries (EPIdemiology of DIAbetes and Ramadan [EPIDIAR] study), it was found that $43 \%$ with type 1 and 79\% with type 2 diabetes fasted for at least 15 days during the month of Ramadan. ${ }^{[16]}$ It is to be believed that to many, this month brings in a sense of calmness and strengthening of social ties. ${ }^{[17]}$ Thus, a step toward addressing the psychosocial support needs of the diabetics could be the establishment of a system where in the patients in those circumstances where fasting could be medically harmful are counseled and informed that they are exempt. Some people might prefer reassurance from religious authorities when deciding not to fast. If Ramadan falls in summer, fasting duration can last for more than 18 hours, in which case fasting in people with diabetes could prove more challenging. If required, diabetic Muslims may be counseled before Ramadan months and help to dissuade from trying to fast by explaining them the importance and legitimacy of breaking the fast in such situations. ${ }^{[18]}$ Rather, physicians might target to counsel Muslim patients about safe fasting, not only before Ramadan but also at their annual diabetic follow-ups and at diagnoses. ${ }^{[19]}$ Apart from this, evidence shows that stress might be relieved by the behavioral modification during Ramadan. ${ }^{[17,20]}$ In Mewat, introduction of trained counselor might be another alternative option who could counsel according to the prescriptions of doctors. Smaller Hindu population in 
Mewat district also exists (i.e., 26\% ${ }^{[2]}$ for which usual recommendation of psychosocial management guidelines as discussed in the article, except specifically related Muslim population, might apply.

\section{PSYCHOLOGICAL ASSESSMENT AND MANAGEMENT}

As Mewat is a resource constraint district [Table 2], concept of trained field psychologist might be introduced to meet the needs of psychological assessment and management of diabetic patients.

The field psychologist could plan and hold sessions at grass root levels like sub-centers or primary health centers to provide psychological management of diabetic and other chronic disorder patients through an integrated approach. Spiritual harmony might also provide some psychological support to the diabetic Meos during the Ramadan months. ${ }^{[17,20]}$ However, expectedly higher prevalence of psychiatric disorders among the diabetic population ${ }^{[21]}$ adds to the expenses of the already poor patients of Mewat and thus might increase their psychosocial and psychiatric management needs. Provision of free, easily accessible psychiatric treatment is need of the hour. If the services are fully utilized by the diabetics, Department of Psychiatry at Shaheed Hasan Khan Mewati Govt. Medical College Nalhar, a new medical college in the district, could fill the gap. For improving utilization of such services, voluntary field mobilizers from among community e.g., Accredited Social Health Activists (ASHAs) ${ }^{[22]}$ could be trained, sensitized, and incentivized.

In the light of existing socio-demographic characteristics in Mewat, time spending behavior change efforts at the patient, family, or community level like family therapy, yoga and meditation, dance therapy are a challenge. As predominant population is Muslim Meos, ${ }^{[2]}$ perhaps the purpose of meditation is achieved, to some extent, by the widely followed practice of religious prayers.

Psychopharmacologic management of diabetics might also be interfered during the month of Ramadan. Fair compliance to these interventions might be achieved in coordination with local religious leaders by disseminating the relevant correct clear messages. Periodic meetings of the doctors with those leaders might be organized to discuss and disseminate such issues for effective and legitimate ways of implementation of the management guidelines without interfering with prevalent religious beliefs and/or practices.
Social Assessment and Management

As described earlier, Mewat is unique in its social structure [Tables 1 and 2]. Mewat is one of the backward districts of the country that severely lags behind in terms of socioeconomic parameters of development. ${ }^{[2]}$ Joint efforts of scaling up socio-economic development and ensuring free drugs in Govt. sector and affordable price drugs in private sector might prove few of the most useful steps at political level for improving adherence to anti-diabetic as well as psychopharmacologic drugs.

As recommended in the guidelines, family structure also has an important role to play in better psychosocial management of diabetics. Poorer literacy among women in comparison to men points toward more influence of heads of families on decisions [Table 1]. As compared with rest of the districts in Haryana, a relatively better indicator in the region is the gender ratio i.e., 907 females per 1000 males [Table 1]. Deputing female and male Medical Social Workers ${ }^{[23]}$ in the field and ensuring liaison with doctors could also facilitate in addressing social and family structure issues for effective implementation of guidelines regarding psychosocial management of diabetes. Mewat Development Agency started a special program for empowerment of women through constituting Self Help Groups (SHGs) from among rural females. Currently, there exist more than 2000 such SHGs in Mewat. ${ }^{[24]}$ Incorporating issues which are in line with the national guidelines like social support for positive health outcomes and psychosocial management of diabetes into the goals of these SHGs could be an effective vehicle for generating the health awareness among women.

Until the community is made well versed with problems of diabetes and related psychosocial management issues in a campaign mode, confidentiality issues must be kept in mind.

Conclusively, for the maximum impact, in Mewat region, the national recommendations of psychosocial management of diabetes in India must be implemented in a well fitted manner according to the existing socio-cultural milieu and as per their practical applicability as discussed above. Necessary community based trials, wherever applicable, are necessary to be conducted in the area to assess the effectiveness of the proposed public health interventions.

\section{REFERENCES}

1. Kalra S, Sridhar GR, Balhara YP, Sahay RK, Bantwal G, Baruah MP, et al. National recommendations: Psychosocial management of diabetes in India. Indian J Endocrinol Metab 2013;17:376-95. 
2. Institute for Human Development. A Baseline Survey of Minority Concentration Districts of India: Mewat (Haryana). New Delhi: Ministry of Minority Affairs, Government of India; 2008.

3. Office of Registrar General and Census Commissioner, India. Census of India 2011: Provisional Population Totals Paper 1 of 2011. New Delhi: Ministry of Home Affairs, Government of India; 2011.

4. Office of Registrar General and Census Commissioner, India. Census of India 2011: Provisional Population Totals Paper 2 of 2011 (India \& States/UTs). New Delhi: Ministry of Home Affairs, Government of India; 2011.

5. Kalra S, Baruah MP, Ranabir S, Singh NB, Choudhury AB, Sutradhar S, et al. Guidelines for ethno-centric psychosocial management of diabetes mellitus in India: The North East consensus group statement. J Soc Health Diabetes 2013;1:9-14.

6. District Administration, Mewat. Chief Medical Officer [document on the Internet]. Nuh: Government of Haryana. Available from: http://mewat.gov.in/pdf/CMO/cmo.pdf. [Updated 2013, June 10; Last accessed on 2013, August 3].

7. Directorate General of Health Services. Indian Public Health Standards (IPHS): Guidelines for District Hospitals (101 to 500 Bedded) Revised 2011. New Delhi: Ministry of Health and Family Welfare, Government of India; 2012.

8. Directorate General of Health Services. Indian Public Health Standards (IPHS): Guidelines for Sub-district/Sub-divisional Hospitals (31 to 100 Bedded) Revised 2012. New Delhi: Ministry of Health and Family Welfare, Government of India; 2012.

9. National Rural Health Mission. List of District Hospitals. [Document on the Internet.] Nuh: Government of Haryana. Available from: http://www.nrhmharyana.org/Writereaddata/userfiles/file/PDFs/ HMIS_MCTS/Annexure-D(ii).pdf. [Updated 2013, June 10; Last accessed on 2013, August 3].

10. Shaheed Hassan Khan Mewati Govt. Medical College Nalhar (Mewat): Hospital. [Document on the Internet.] Nalhar: Government of Haryana. Available from: http://www.gmcmewat. ac.in/index.php. [Updated 2013, June 10; Last accessed on 2013, August 3].

11. Directorate General of Health Services. Indian Public Health Standards (IPHS): Guidelines for Community Health Centres (Revised 2012). New Delhi: Ministry of Health and Family Welfare, Government of India; 2012.

12. Directorate General of Health Services. Indian Public Health Standards (IPHS): Guidelines for Primary Health Centres (Revised 2012). New Delhi: Ministry of Health and Family Welfare, Government of India; 2012.
13. Directorate General of Health Services. Indian Public Health Standards (IPHS): Guidelines for sub-centres (Revised 2012). New Delhi: Ministry of Health and Family Welfare, Government of India; 2012.

14. Radio Mewat: Programming: Swasthaya ki Baat. [Document on the Internet.] Mewat: Community Radio Association; 2010. Available from: http://www.radiomewat.org/. [Last accessed on 2013, August 2].

15. Al-Islam S, Ahmad T, Halim A, Taymiyyah IB. The Nature of Fasting [e-book]. Hyderabad: Darussalam Publishers and Distributers. Available from: http://www.islamcan.com/ramadan/ebooks/ en_The_Nature_of_Fasting.pdf. [Last accessed on 2013, August 2].

16. Salti I, Bénard E, Detournay B, Bianchi-Biscay M, Le Brigand C, Voinet $\mathrm{C}$, et al. A population-based study of diabetes and its characteristics during the fasting month of Ramadan in 13 countries: Results of the epidemiology of diabetes and Ramadan 1422/2001 (EPIDIAR) study. Diabetes Care 2004;27:2306-11.

17. Daradkeh TK. Parasuicide during Ramadan in Jordan. Acta Psychiatr Scand 1992;86:253-4.

18. Sheikh A, Wallia S. Ramadan fasting and diabetes. BMJ 2007;335:613-4.

19. Hui E, Bravis V, Hassanein M, Hanif W, Malik R, Chowdhury TA, et al. Management of people with diabetes wanting to fast during Ramadan. BMJ 2010;340:c3053.

20. Afifi ZE. Daily practices, study performance and health during the Ramadan fast. J R Soc Health 1997;117:231-5.

21. Maia AC, Braga Ade A, Brouwers A, Nardi AE, Oliveira e Silva AC. Prevalence of psychiatric disorders in patients with diabetes types 1 and 2. Compr Psychiatry 2012;53:1169-73.

22. Ministry of Health and Family Welfare. National Rural Health Mission (2005-2012): Mission Document. New Delhi: Government of India; 2005.

23. Hazra A. Current prospects of social work in India. Employment News 2013;July 27-August 2.

24. Mewat Development Agency. Community \& Women Empowerment. [Document on the Internet]. Nuh, Mewat: Government of Haryana. Available from: http://mda.nic.in/SHG\%20Information.htm. [Updated 2013, July 31; Last accessed on 2013, August 3].

How to cite this article: Kumar A, Goel PK, Vashisht BM, Mittal K. Psychosocial management of diabetes: Applicability of national guidelines to Mewat, an underserved region of Haryana. J Soc Health Diabetes 2014;2:14-7.

Source of Support: Nil. Conflict of Interest: None declared. 